\title{
miR-21 Promotes Fibrogenesis in Peritoneal Dialysis
}

Melisa Lopez-Anton, ${ }^{*}$ Mark Lambie, ${ }^{\dagger}$ Manuel Lopez-Cabrera, ${ }^{\S}$ Claus P. Schmitt, ${ }^{\circledR}$ Vicente Ruiz-Carpio, ${ }^{\S}$ Maria Bartosova, Betti Schaefer, ${ }^{\top}$ Simon Davies, ${ }^{\dagger}$ Timothy Stone, ${ }^{*}$ Robert Jenkins, ${ }^{*}$ Philip R. Taylor, ${ }^{*}$ Nicholas Topley, ${ }^{*}$ Timothy Bowen, ${ }^{*}$ and Donald Fraser*

From the Wales Kidney Research Unit,* Division of Infection and Immunity, School of Medicine, College of Biomedical and Life Sciences, Cardiff University, Cardiff, United Kingdom; Keele University, ${ }^{\dagger}$ Keele, United Kingdom; the Centro de Biología Molecular Severo Ochoa, ${ }^{\S}$ the Spanish National Research Council, Madrid, Spain; and the University of Heidelberg, "Heidelberg, Germany

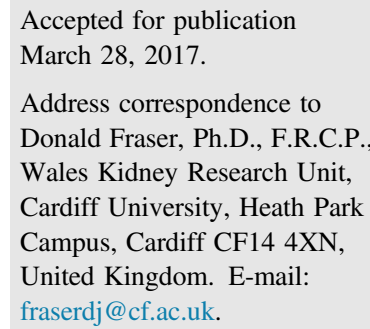

\begin{abstract}
Peritoneal dialysis (PD) is a life-saving form of renal replacement therapy for those with end-stage kidney disease. Mesothelial cells (MCs) line the peritoneal cavity and help define peritoneal response to treatment-associated injury, a major reason for treatment failure. miRNAs are important regulators, but their roles in peritoneal fibrosis are largely unknown. In this study, miR-21 was one of the most abundant miRNAs in primary MCs, and was up-regulated by the profibrotic cytokine transforming growth factor- $\beta 1$ and in PD effluent-derived MCs exhibiting mesenchymal phenotypic change. Increased miR-21 was found in peritoneal membrane biopsy specimens from $\mathrm{PD}$ patients compared to healthy controls (PD biocompatible, 5.86 $\times, P=0.0001$; PD conventional, $7.09 \times, P<0.0001, n=11$ per group). In PD effluent from a cohort of 230 patients, miR-21 was higher in those receiving the therapy long-term compared to new starters $(n=230$, miR-21 3.26×, $P=0.001)$ and associated with icodextrin use $(R=0.52 ; 95 \%$ CI, $0.20-0.84)$, peritonitis count $(R=0.16 ; 95 \%$ CI $0.03-0.29)$, and dialysate cytokines. miR-21 down-regulated programmed cell death 4 and programmed cell death 4 protein was decreased in peritoneal membrane biopsy specimens from PD patients compared to healthy controls. New miR-21 targets were identified that may be important during PD fibrogenesis. These data identify miR-21 as an important effector of fibrosis in the peritoneal membrane, and a promising biomarker in the dialysis effluent for membrane change in patients receiving PD. (Am J Pathol 2017, 187: 1537-1550; http://dx.doi.org/10.1016/j.ajpath.2017.03.007)
\end{abstract}

Approximately 650,000 end-stage kidney disease patients in the United States depend on renal replacement therapy to keep them alive, a number increasing by $5 \%$ to $8 \%$ per year. Dialysis treatment accounts for $1 \%$ to $2 \%$ of national health care budgets, and may be provided by hemodialysis, in which the blood is purified across an artificial membrane, or by peritoneal dialysis (PD). In PD, exchange between the blood and the dialysate instilled in the patient's own peritoneal cavity occurs across the peritoneal membrane. Thus, PD leads to constant exposure of the peritoneal membrane to bioincompatible PD solutions and a basal inflammatory state, resulting in membrane damage that may progress to treatment failure. ${ }^{1}$ Alterations in mesothelial cell (MC) phenotype, including acquisition of a mesenchymal phenotype and mesothelial cell loss, are an important determinant of these sequelae, ${ }^{2}$ leading to increased synthesis of extracellular matrix components and release of proinflammatory and proangiogenic factors. ${ }^{3} \mathrm{MCs}$ are also detectable in the spent dialysate, and acquire a progressively nonepithelioid phenotype with longer-duration dialysis. ${ }^{4}$ Cells in the deeper layers of the peritoneal tissue, including the stromal fibroblast population, may also make key contributions to fibrogenesis. ${ }^{5}$

Induction of in vitro and in vivo mesenchymal transdifferentiation by transforming growth factor (TGF)- $\beta 1$ has been well documented in the peritoneal membrane and other

\footnotetext{
Supported by Marie Curie Innovative Training Network grant 287813, European Training and Research in Peritoneal Dialysis.
}

Disclosures: None declared. 
tissues and organs. ${ }^{3,6,7}$ TGF- $\beta 1$ overexpression induces structural and functional membrane alterations in rat and mouse peritoneum, ${ }^{7,8}$ and intraperitoneal inhibition of TGF$\beta 1$ preserves peritoneal morphology and function in this model. ${ }^{3}$ TGF- $\beta 1$-driven phenotypic change in primary MCs is therefore a valuable model to study mechanisms of peritoneal fibrosis progression associated with PD therapy.

miRNAs are short, noncoding RNAs that regulate gene expression at the post-transcriptional level. One miRNA may regulate the expression of hundreds of target mRNAs, profoundly affecting cell phenotype and function. Alterations in miRNA expression have been described in a wide range of in vitro and in vivo models. ${ }^{10}$ Studies on miRNA expression in different model systems and body fluids have emphasized their potential as therapeutic targets and disease biomarkers. ${ }^{11-14}$ Mesothelial cell miRNA expression, function, and role of miRNAs in peritoneal fibrosis are largely unknown, and recent studies have begun to address this. ${ }^{15}$ Quantification of seven miRNAs in peritoneal dialysis effluent (PDE)-derived cells from 28 prevalent PD patients found correlation with peritoneal transport characteristics. ${ }^{16}$ Enforced expression of miR-29b inhibited peritoneal fibrosis in a mouse model of daily intraperitoneal PD fluid infusion. ${ }^{2}$ miR-30a was down-regulated in a rat PD infusion model, and decreased in peritoneal membrane from 10 established PD patients. ${ }^{17}$ In this last study, miR-30a targeted Snail, a key regulator of mesothelial-tomesenchymal transition (MMT) via down-regulation of adherens (E-cadherin) and tight junctions (claudin-1, occluding, and zonula occludens protein 1). ${ }^{18,19}$ miR-589 was down-regulated in six PD patients treated for $>6$ months, ${ }^{20}$ and miR-200c was down-regulated in PDEderived cells from 16 patients undergoing PD for $>6$ months. ${ }^{21}$ Collectively, these studies are suggestive that miRNAs are important regulators of MC phenotype and fibrogenesis in PD patients. Measurement of miRNAs in PDE may, therefore, be valuable in predicting the clinical course. However, this previous research has largely taken a literature-based candidate miRNA approach, and drawn conclusions from analyses of small numbers of patientderived samples.

In this study, miRNAs were studied in mesothelial cells cultured in vitro and ex vivo from peritoneal dialysis patients, and linked to measurements conducted in the peritoneal dialysis effluent and the peritoneal membrane itself, to provide definitive identification of miRNAs expressed by MCs and changes occurring as a consequence of peritoneal dialysis, and to link these to likely miRNA functions. MC miRNA profiles and responses to TGF- $\beta 1$ were characterized in vitro, and increased miR-21 was demonstrated in MCs incubated with TGF- $\beta 1$, and in separate experiments in MCs exhibiting a mesenchymal phenotype derived from PDE. In a study of 44 peritoneal membrane biopsy specimens, increased miR-21 was found in peritoneal membrane from PD patients compared with healthy and uremic controls. In PDE from a cohort of 230 patients taken from The
Global Fluid Study, miR-21 associated with clinical parameters indicative of membrane change and treatment failure. Analysis of miRNA targets identified miR-21 regulation of tumor suppressor programmed cell death 4 (PDCD4) in MCs and in peritoneal membrane biopsy specimens from PD patients. Finally, four previously unreported miR-21 targets were identified, linked to the mesothelial to mesenchymal process occurring as a consequence of PD treatment.

\section{Materials and Methods}

\section{Cell Culture, TGF- $\beta 1$ Treatment, and Cell Transfection}

Appropriate ethical approval was in place for all experiments involving specimens derived from patients, and all patients gave informed consent for use of their specimens for research purposes. Human peritoneal mesothelial cells (HPMCs) were obtained from enzymatically degraded specimens of human omentum, as previously reported. ${ }^{22}$ In brief, specimens of omentum from patients undergoing abdominal surgery were washed in phosphate-buffered saline before incubation with $0.125 \%$ (w/v) trypsin, $0.01 \%$ $(\mathrm{w} / \mathrm{v})$ EDTA, and $0.1 \%(\mathrm{w} / \mathrm{v})$ glucose for 20 minutes at $37^{\circ} \mathrm{C}$ with continuous rotation. After incubation, the suspension was centrifuged at $50 \times g$ for 5 minutes at $4^{\circ} \mathrm{C}$. The cell pellet was washed once in culture medium, then resuspended in culture medium and seeded in tissue culture flasks. For ex vivo analysis, mesothelial cells derived from PD patients' effluents were cultured and analyzed, as described. ${ }^{4}$ In brief, human mesothelial cells from peritoneal dialysis effluent were obtained by centrifugation and passaged in culture two times at 10- to 15-day intervals. Morphological features of cells were compared and remained stable through passage. Mesothelial cells were characterized as of epithelial or fibroblast-like character, as previously reported. ${ }^{4}$

For miRNA gain-of-function and loss-of-function experiments, mirVana miRNA mimic and mirVana miRNA inhibitors were used at concentrations of 5,10 , and $20 \mathrm{pmol} / \mathrm{L}$ for target mRNA measurements 48 hours after transfection. mirVana miRNA mimic $(5 \mathrm{pmol} / \mathrm{L})$ was used for protein quantification 72 hours after transfection.

\section{Peritoneal Membrane Study}

Formalin-fixed, paraffin-embedded (FFPE) peritoneal membrane samples from 44 pediatric patients (1.83 to 19.16 years old) included in the International Pediatric PD Biopsy Study were used in this analysis (http://www.clinicaltrials. gov; NCT01893710). Patients were matched for age, sex, PD duration, and submesothelial thickness. Patients with previous peritonitis, systemic diseases, and abdominal surgery other than Tenckhoff catheter insertion, revision, or kidney transplantation were excluded. Comprehensive individual clinical data were collected and assessed before 
analysis to exclude disparity regarding disease susceptibility or comorbidity. Approval was obtained from local ethics committees, and written informed consent was obtained from patients and parents. FFPE samples were cresyl violet stained, and the mesothelial and submesothelial compact zones were manually microdissected from a total of $40 \mu \mathrm{m}$ section using a Leica RM 2165 rotary sliding microtome (Leica Biosystems, Wetzlar, Germany) and a Leica S8 APO stereo microscope.

\section{PD Effluent Study}

The Global Fluid Study is an international, multicenter, prospective, observational cohort study of 959 patients. $^{23}$ Samples from a single center were used for miRNA analysis, to exclude center effects, and the first sample collected from each patient was analyzed. Dialysate cytokine levels had been measured previously by electrochemiluminescence. ${ }^{23}$ Four-hour dwell dialysate samples were stored at $-80^{\circ} \mathrm{C}$ and thawed on ice. Aliquots $(600 \mu \mathrm{L})$ were centrifuged at $12,000 \times g$ at $4^{\circ} \mathrm{C}$ for 20 minutes before RNA extraction. Extreme outliers $(n=3)$ were retested and then excluded, as the results from these samples showed high variance, consistent with sample degradation before analysis.

\section{RNA Isolation}

For quantitative RT-PCR (RT-qPCR) analysis, miRNA and mRNA array HPMCs were lysed in TRI reagent (Ambion, Thermo Fisher Scientific, Waltham, MA), and RNA was extracted as recommended by the manufacturer. RNA from PDE was isolated from $500 \mu \mathrm{L}$ of fluid using the mirVana PARIS Kit (Ambion, Thermo Fisher Scientific). To monitor extraction efficacy, 0.5 pmol of cel-miR-39 (Life Technologies; MC10956) was spiked in to all PDE samples after addition of $2 \times$ denaturing solution. FFPE samples were processed immediately after sectioning using RecoverAll total nucleic acid isolation kit (Ambion, Thermo Fisher Scientific), according to the manufacturer's recommendations. MS2 RNA carrier ( $1 \mu \mathrm{g}$; Roche, Basel, Switzerland) was added to biopsy extractions, to improve RNA recovery.

\section{RT-qPCR Analysis}

cDNA was synthesized from $2 \mu \mathrm{g}$ of total RNA using the High Capacity cDNA reverse transcription kit (Life Technologies). Alternatively, $10 \mathrm{ng}$ of total RNA was used for cellular miRNAs. For PDE and FFPE samples, constant volumes of RNA were used. RT-qPCR was performed in a ViiA 7 Real-Time PCR System (Applied Biosystems, Waltham, MA) using Power SYBR Green PCR master mix (Applied Biosystems). The primers used are shown in Table 1. TaqMan Universal Master Mix II (Applied Biosystems) and specific primers for miR-21 and miR-191 (Applied Biosystems) were used for miRNA analysis. ${ }^{24}$ mRNA and miRNA expression levels were normalized to
Table 1 RT-qPCR Primer Sequences

\begin{tabular}{|c|c|}
\hline Gene name & Primer sequence \\
\hline \multirow[t]{2}{*}{$\mathrm{CDH} 1$} & F: 5'-ТСССААТАСАТСТСССТТСАСА-3' \\
\hline & R: 5'-АСCCACСTCTAAGGCCATCTTT-3' \\
\hline \multirow[t]{2}{*}{ TJP1 } & F: 5'-GGAGAGGTGTTCCGTGTTGT-3' \\
\hline & R: 5'-GGCTAGCTGCTCAGCTCTGT-3' \\
\hline \multirow[t]{2}{*}{$O C L N$} & F: 5'-TAAATCCACGCCGGTTCCTGAAGT- $3^{\prime}$ \\
\hline & R: 5'-AGGTGTCTCAAAGTTACCACCGCT-3' \\
\hline \multirow[t]{2}{*}{ CLDN1 } & F: 5'-CGGGTTGCTTGCAATGTGC-3' \\
\hline & R: 5'-CCGGCGACAACATCGTGAC-3' \\
\hline \multirow[t]{2}{*}{ FN1 } & F: 5'-CCGAGGTTTTAACTGCGAGA-3' \\
\hline & R: 5'-TCACCCACTCGGTAAGTGTTC- $3^{\prime}$ \\
\hline \multirow[t]{2}{*}{ COL1A1 } & F: 5'-CATGTTCAGCTTTGTGGACCTC-3' \\
\hline & R: 5'-TTGGTGGGATGTCTTCGTCT-3' \\
\hline \multirow[t]{2}{*}{ SNAI1 } & F: 5'-TTTACCTTCCAGCAGCCCTA-3' \\
\hline & R: 5'-GGACAGAGTCCCAGATGAGC-3' \\
\hline \multirow[t]{2}{*}{ ACTA2 } & F: 5'-AACTGGGACGACATGGAAA-3' \\
\hline & R: 5'-AGGGTGGGATGCTCTTCAG-3' \\
\hline \multirow[t]{2}{*}{ GAPDH } & F: 5'-CCTCTGACTTCAACAGCGACAC-3' \\
\hline & R: $5^{\prime}$-TGTCATACCAGGAAATGAGCTTGA-3' \\
\hline \multirow[t]{2}{*}{ PDCD4 } & F: 5'-TGGATTAACTGTGCCAACCA-3' \\
\hline & R: 5'-TСТСАААТGСССТTTСАТСС-3' \\
\hline \multirow[t]{2}{*}{ SPRY1 } & F: 5'-AGATGCATGCCAGGTTTCCA-3' \\
\hline & R: 5'-TAACGAACTGCCACTGCCAT-3' \\
\hline \multirow[t]{2}{*}{ PTEN } & F: 5'-CGGCAGCATCAAATGTTTCAG-3' \\
\hline & R: 5'-AACTGGCAGGTAGAAGGCAACTC-3' \\
\hline \multirow[t]{2}{*}{ LATS2 } & F: 5'-CAGATTCAGACСTCTCCCGT-3' \\
\hline & R: 5'-CTTAAAGGCGTATGGCGAGT-3' \\
\hline \multirow[t]{2}{*}{ STK40 } & F: 5'-CCAGTGCCCTTGCCTCATAA-3' \\
\hline & R: 5'-AATCTCGGCTCAAAAGGGCA-3' \\
\hline
\end{tabular}

Primer sequences designed and used for RT-qPCR in this study.

F, forward; GAPDH, glyceraldehyde-3-phosphate dehydrogenase; PDCD4, programmed cell death $4 ; \mathrm{R}$, reverse; RT-qPCR, quantitative RT-PCR; $\alpha-S M A$, $\alpha$-smooth muscle actin; Z0-1, zonula occludens protein 1 .

glyceraldehyde-3-phosphate dehydrogenase and miR-191, respectively. The relative changes in gene expression were analyzed by the $2^{-\Delta \Delta \mathrm{Ct}}$ method. ${ }^{25}$ Data is normalized to the reference gene, and reported as amount detected in the sample relative to amount detected in the control (relative quantification).

\section{miRNA and mRNA Microarrays}

Microarray assays were performed on HPMCs derived from four independent donors. miRNA expression was measured in control samples and after $1 \mathrm{ng} / \mathrm{mL}$ of TGF- $\beta 1$ treatment for 48 hours. ${ }^{3,26-29}$ Cellular phenotype was confirmed by analysis of eight molecular markers chosen as indicators of epithelial (E-cadherin, zona occludens protein 1, claudin and occludin) and mesenchymal (fibronectin, collagen 1, snail and alpha smooth muscle actin) characteristics. ${ }^{3,27-30} \mathrm{~A}$ total of $1 \mu \mathrm{g}$ in a volume of $\leq 2 \mu \mathrm{L}$ of total RNA from each sample was subsequently used for Toray microarray analysis, performed by Central Biotechnology Services at Cardiff University (Cardiff, UK), as described previously. ${ }^{30}$ For ex vivo mRNA microarray analysis, patient-derived $\mathrm{MC}$ samples were classified as E phenotype (nine samples) and 
NE phenotype (eight samples). ${ }^{29}$ Four omentum-derived MC, samples were taken as controls. Label dye-swap design was used in these experiments using the Quick Amp Labeling Kit, two-color (Agilent Technologies, Santa Clara, CA). mRNA microarray analysis was performed using the Whole Human Genome Microarrays Kit $4 \times 44 \mathrm{~K}$ (Agilent Technologies), according to the manufacturer's instructions: $825 \mathrm{ng}$ of cRNA (Cy3-cRNA and Cy5-cRNA) was incubated with blocking agent and fragmentation buffer, 30 minutes, $60^{\circ} \mathrm{C}$. Hybridization was performed in hybridization buffer at $65^{\circ} \mathrm{C}$ for 17 hours in darkness and with constant stirring. Subsequently, slides were introduced in different saline buffer stringencies, stabilization solution, and dried as indicated by Agilent Technologies. Arrays were scanned on the Agilent Technologies G2505B Micro Array Scanner at 5-nm resolution.

\section{Immunoblotting}

Whole-cell protein samples were collected using RIPA Lysis Buffer (sc-24948; Santa Cruz Biotechnology, Dallas, TX), and protein concentrations were determined using BioRad Protein Assay (5000001; BioRad, Hercules, CA). Protein $(15 \mu \mathrm{g})$ in $3 \times$ Reducing Loading Buffer was heated at $95^{\circ} \mathrm{C}$ for 5 minutes, ice cooled, separated by $7.5 \%$ SDSPAGE, and transferred onto nitrocellulose membranes, which were subsequently blocked using $5 \%$ bovine serum albumin with $0.1 \%$ Tween 20 for 1 hour. Primary and secondary antibodies were PDCD4 (1:1000; 9535 D29C6; Cell Signaling Technology, Danvers, MA), glyceraldehyde3-phosphate dehydrogenase (1:2000; ab9485; Abcam, Cambridge, UK), goat anti-rabbit IgG-horseradish peroxidase (1:10000; sc-2004; Santa Cruz Biotechnology), and goat anti-mouse $\mathrm{IgG}$-horseradish peroxidase (1:10000; sc2005; Santa Cruz Biotechnology) incubated in $0.1 \%$ bovine serum albumin with $0.1 \%$ Tween- 20 overnight. Immunoblots were developed using WesternBright ECL Spray (K12049-D50; Advansta, Menlo Park, CA), images were captured via C-DiGit Chemiluminescent Western Blot Scanner (LI-COR Biosciences, Lincoln, NE), and densitometry analysis was conducted using Image Studio Software version 5.2 (LI-COR Biosciences).

\section{Immunohistochemical Staining}

Immunohistochemical staining of peritoneal membrane study samples was performed on sections (5 $\mu \mathrm{m}$ thick) mounted on glass slides, as previously described. ${ }^{31}$ After deparaffinization and rehydration, the sections were incubated in 3\% hydrogen peroxide. Heat-induced antigen retrieval was performed in a microwave oven, using $0.005 \mathrm{~mol} / \mathrm{L}$ citrate buffer $(\mathrm{pH} 6)$. Polyclonal rabbit anti-p-SMAD2/3 (Santa Cruz Biotechnology; sc-11769) was incubated for 1 hour at room temperature $(1: 100)$. Incubation with biotinylated secondary reagents (Vector, Peterborough, UK) for 30 minutes was followed by addition of $\mathrm{ABC}$ reagent (Vector) and detection using $3^{\prime} 3^{\prime}$ diaminobenzidine (Sigma, Taufkirchen, Germany) with hematoxylin counterstain.

\section{Aperio Analysis}

Immunohistochemical images were captured and evaluated using Aperio Precision Image Analysis Software (Aperio Technologies, Inc., Vista, CA). All slides were scanned at an original magnification of $\times 40$ using a whole slide imaging system (ScanScope CS; Aperio Technologies, Inc.). Automated quantitative analyses were performed using the Aperio Image Analysis Software version 9 (Aperio Technologies, Inc.) and viewed by Image Scope version 11.2.0.780 (Leica Biosystems). Immunohistochemical stainings were evaluated using the Aperio Positive Pixel Count Algorithm version 9 for quantification of the amount of positive pixels per scanned virtual slide. Intensity ranges for weak, medium and strong signals and negative pixels were validated for each specific staining. Input algorithm parameters are specific color ranges in the HSI colorspace (hue value, 0.1 ; hue width, 0.5 ), and intensity ranges to differentiate between weak, medium, strong, and negative staining. Intensity thresholds (upper/lower limit) were as follows: weak, 220/175; medium, 175/100; strong, 100/0; and negative, 255/220. Thresholds were optimized and validated specifically for p-SMAD2/3. Positivity was calculated using numbers of negative pixels $\left(\mathrm{N}_{\mathrm{n}}\right)$ and total pixels ( $\left.\mathrm{N}_{\text {total }}\right)$ using the formula: $\left(\mathrm{N}_{\text {total }}-\mathrm{N}_{\mathrm{n}}\right) /\left(\mathrm{N}_{\text {total }}\right)$.

\section{Statistical Analysis}

Differences between two individual experimental groups of normally distributed values were compared by two-tailed $t$-test; for multiple comparisons, analysis of variance, followed by post hoc Holm-Sidak test, was used. For clinical data, Pearson's correlations were used for normally distributed variables, transformed as necessary, and Spearman's for other variables. Multivariable linear regression with backwards-stepwise variable selection was performed for natural log transformed miR-21 variables, and to avoid problems with suppressor effects, dialysate cytokine values were entered as a block.

miRNA array data were analyzed using GenePix Pro software version 6 (Molecular Devices, Sunnyvale, CA); spot data were considered valid probe hybridization when signal intensity was greater than the mean intensity of the background signal plus 2 SDs. A normalization step for each specific miRNA adjusted median value was subsequently performed. The relative miRNA expression levels were determined by comparing the mean signal intensity of the real hybridized spots with their average value across the microarray experiment. To reliably compare data from multiple chips, a quantile normalization was applied to the values. These miRNA profiling data sets can be found in 
Gene Expression Omnibus (https://www.ncbi.nlm.nih.gov/ geo; accession number GSE79006).

mRNA array data processing and normalization was performed using the Babelomics 5 software (Computational Genomics Department, Prince Felipe Research Center, Valencia, Spain). ${ }^{29,32}$ Fluorescence raw signal from each probe was corrected with the subtraction of local background and normalized with the loess method (within arrays) or the quantile method (between arrays). Fold change for a gene was determined as a quotient between normalized data from samples under study. Statistics for differential expression were obtained with Limma One Class or Limma Two Class test and corrected for multiple test with false discovery rate (Benjamini and Hochberg). Genes with fold change $\leq 0.5$, and false discovery rate $\leq 0.01$, were considered repressed. mRNA array changes displayed herein indicate gene rather than transcript variant level. mRNA array results presented in this article can be found in Gene Expression Omnibus (https://www.ncbi.nlm.nih.gov/ geo; accession number GSE92455). ${ }^{29}$

\section{Results}

\section{Mesothelial miRNA Profile Is Altered by TGF- $\beta 1$}

Before profiling overall mesothelial miRNA expression, a characterization of responses to TGF- $\beta 1$ was performed using primary cultures of mesothelial cells with replicate experiments using cells from different omental donors (Supplemental Figures S1 and S2). These results

\section{A}

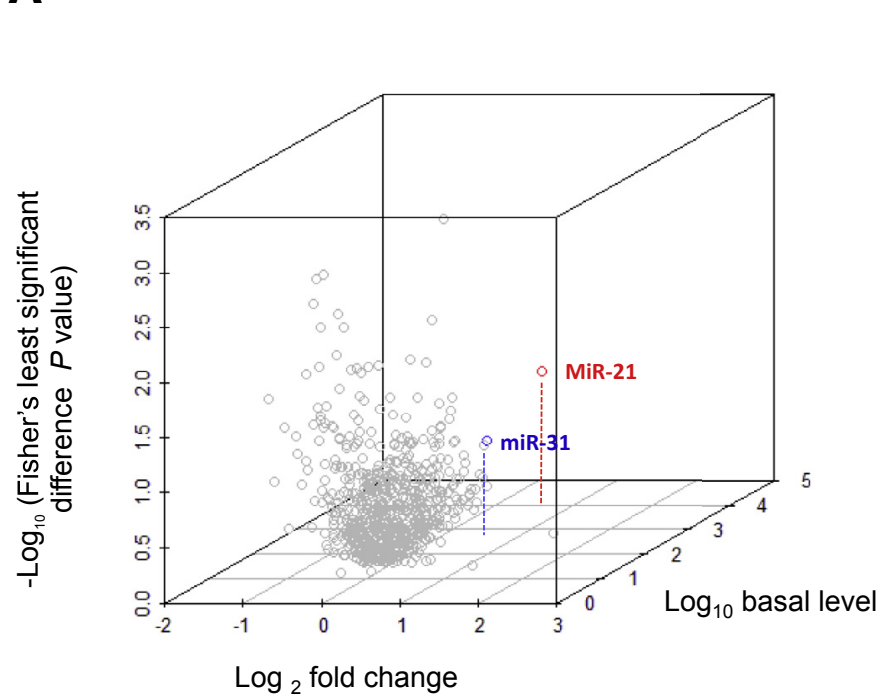

demonstrated that in primary HPMCs from multiple donors, $1 \mathrm{ng} / \mathrm{mL}$ of TGF- $\beta 1$ induced changes consistent with an MMT process after 48 hours. Global miRNA expression was then quantified by hybridization array. Four independent biological replicates from different donors displayed high consistency (Supplemental Figure S3). A total of 699 miRNAs were detected in at least three samples and were included in subsequent analysis. Of 699 miRNAs, 95 were differentially regulated by TGF- $\beta 1$. miR- 21 and miR31 were highly expressed by HPMCs and induced by TGF$\beta 1$ treatment (Figure 1A). miR-29b, previously shown to limit fibrosis when overexpressed in a mouse PD fluid infusion model, ${ }^{2}$ was detected at high signal intensity, but no significant change was observed in response to TGF- $\beta 1$ (fold change, $0.95 \times ; P=0.61$ ). Additional miRNAs previously associated with peritoneal membrane transport change and fibrosis were detected at low signal intensity in this profile and did not change significantly in response to TGF- $\beta 1$ (including miR-15a, miR-17, miR-30, miR-192, miR-200c, miR-377, and miR-589). ${ }^{2,16-21}$

Up-regulation of miR-21 and miR-31 in primary HPMCs was validated using miRNA-specific TaqMan RT-qPCR assays (fold change: miR-21, $1.8 \times, P=0.012$; miR-31, $1.7 \times, \quad P=0.004$ ) (Figure $1 \mathrm{~B}$ and Supplemental Figure S4A). Subsequently, miR-21 and miR-31 expression levels were evaluated in PDE-derived HPMCs cultured ex vivo, divided as previously described ${ }^{4}$ into those exhibiting phenotypic changes consistent with early (E, epithelial phenotype) or late (NE, nonepithelial phenotype) mesothelial to mesenchymal transition. miR-21 exhibited a stepwise
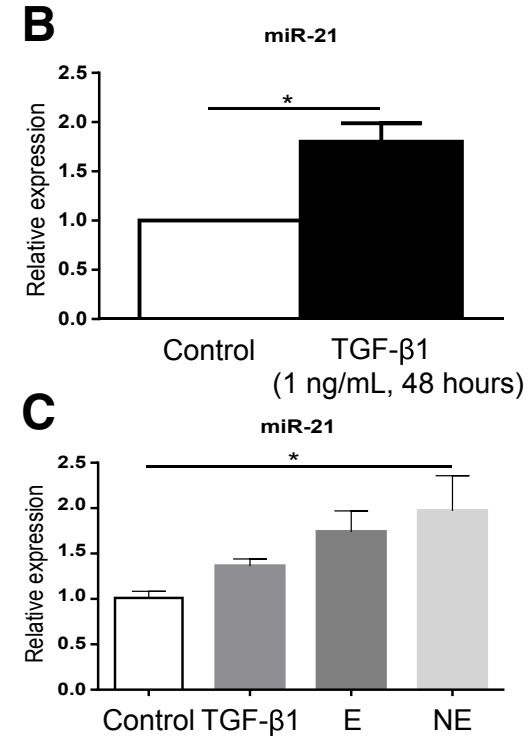

Figure 1 miRNA profiling in transforming growth factor (TGF)- $\beta 1-$ stimulated HPMCs and miRNA changes confirmation in in vitro and ex vivo models. A: Three-dimensional scatter plot of miRNA expression after $1 \mathrm{ng} / \mathrm{mL}$ of TGF- $\beta 1$ treatment for 48 hours $\left[x\right.$ axis: $\log _{2}$ fold change of the normalized miRNA signal (mean of at least three replicates); $y$ axis: $-\log _{10} P$ value obtained from one-way analysis of the variance, followed by Fisher's least significant difference post hoc analysis; $z$ axis: $\log _{10}$ of the level of baseline expression in mesothelial cells]. B: miR-21 expression validation. C: Relative expression of miR-21 in control omentum-derived mesothelial cells (HPMCs), TGF- $\beta 1$ treated $(1 \mathrm{ng} / \mathrm{mL}, 48$ hours), and cultured peritoneal effluent derived (PDE) cells with epithelial (E) and nonepithelial (NE) phenotype. Expression of miR-21 was analyzed by quantitative RT-PCR and normalized to miR-191 expression. Data were analyzed by paired $t$-test or one-way analysis of variance, followed by post hoc Holm-Sidak test comparing each condition mean with the control omentum-derived mean (B and C). Data are expressed as means \pm SEM. $n=5$ independent donor experiments (B and $\mathbf{C}$ ). ${ }^{*} P<0.05$. 
A
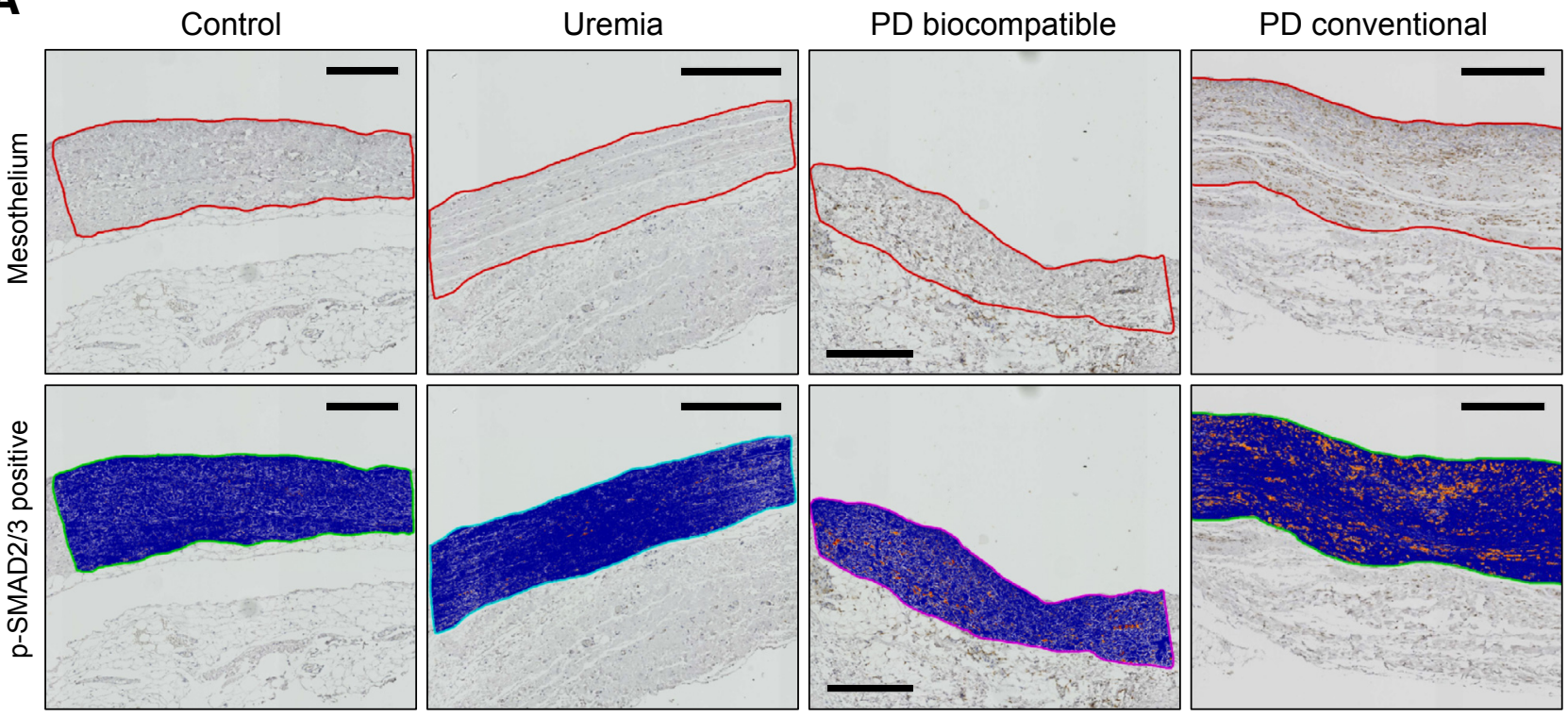

B

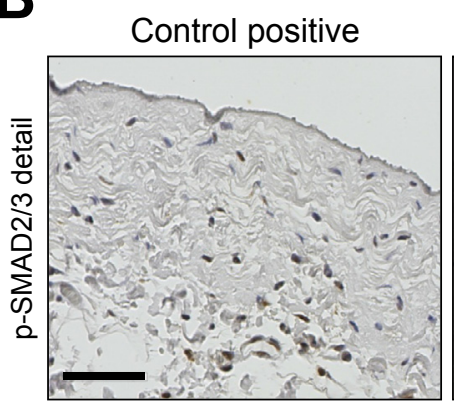

Control negative

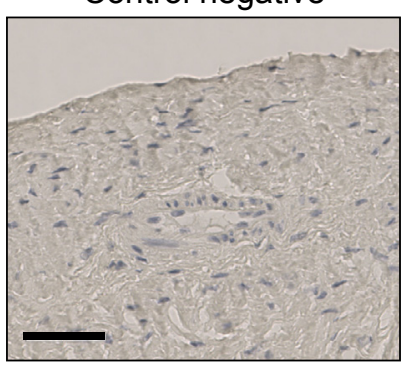

C
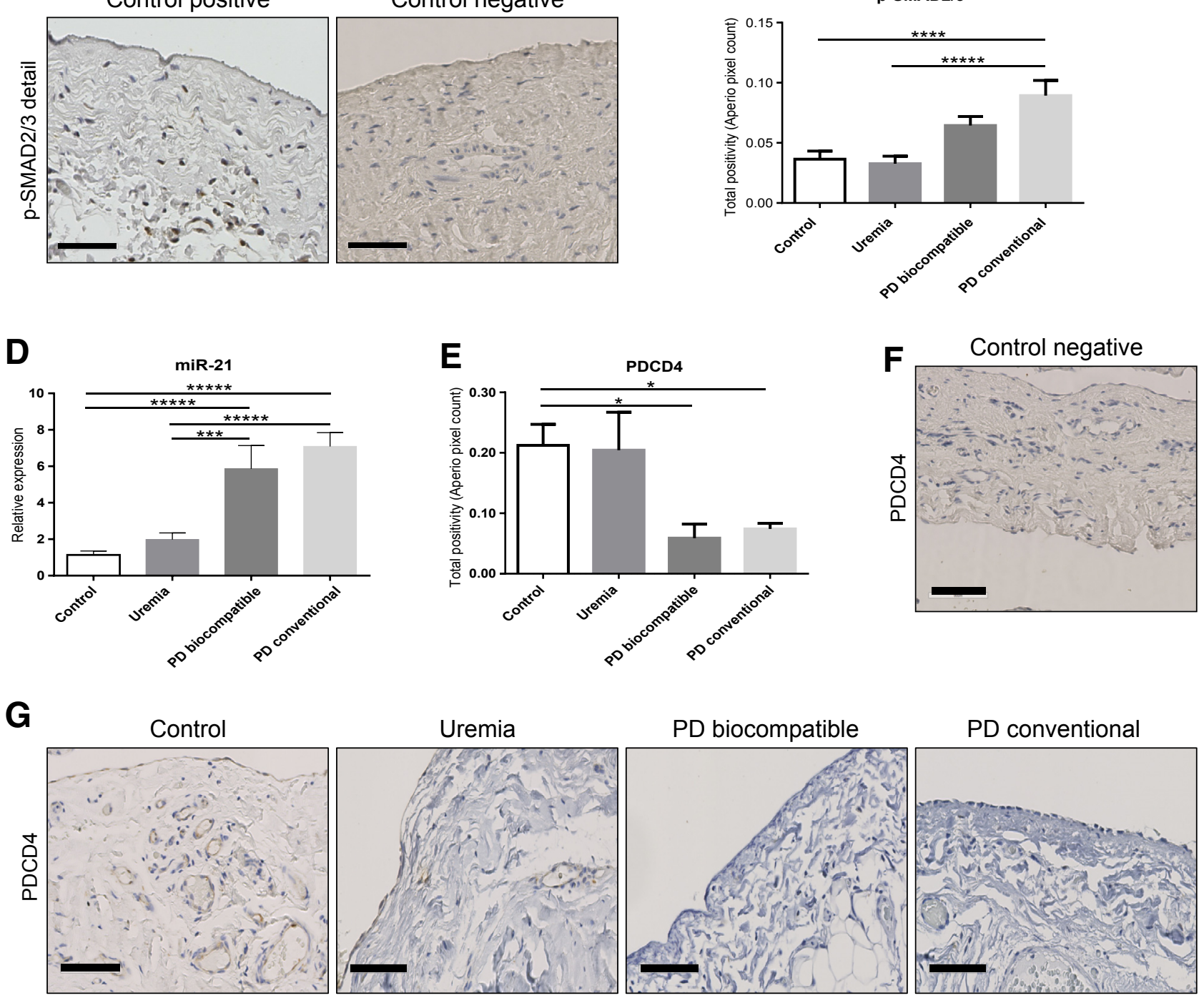
increase in expression through cells of progressively more mesenchymal phenotype (control, incubated with TGF- $\beta 1$, effluent-derived epithelioid, effluent-derived nonepithelioid) (Figure 1C). Elevation of miR-31 in this model was also confirmed (Supplemental Figure S4B).

\section{TGF- $\beta 1$ Signaling Is Activated, and miR-21 Expression Is Increased, in PD Patient Peritoneal Membrane Biopsy Specimens}

TGF- $\beta 1$ signaling and miR-21 and miR-31 expression were analyzed in the mesothelial and submesothelial cell layers of patients undergoing PD. To evaluate the effects of the therapy, distinct from associated vascular pathology or other comorbidity that may be present in biopsy specimens from adult patients, samples from the International Pediatric Membrane Biopsy Registry were studied. Children undergoing PD with conventional and biocompatible fluids were examined, and compared with uremic and nonuremic controls $(n=11$ per group; mean age at biopsy: PD conventional, 9.1 years; PD biocompatible, 8.9 years; control uremic, 9.6 years; control nonuremic, 8.0 years; mean duration of PD: PD conventional, 30 months; PD biocompatible, 31 months). $\alpha$-Smooth muscle actin staining was used as an indicator of fibrogenesis in these samples (Supplemental Figure S5), whereas SMAD2 and SMAD3 phosphorylation were determined as a measure of TGF- $\beta 1$ activity. Phospho-SMAD2/3 staining of FFPE samples was measured using Aperio Precision Image Analysis Software and a count algorithm for positive pixel detection together with positive and negative controls (Figure 2, A-C). The mesothelial and submesothelial compact zone of PD patients displayed enhanced TGF- $\beta 1$ pathway activation compared with controls (Figure 2, A-C). Enhanced p-SMAD2/3 signal was observed in the mesothelium of PD patients under conventional PD fluid treatment compared with controls (Figure 2C). miRNA analysis of manually microdissected FFPE samples also showed an increase in miR-21 expression in the mesothelium of PD patients (Figure 2D). Significant up-regulation of miR-21 was evident after PD treatment when all of the groups were compared with controls (Figure 2D). Because of a high variability between samples in the control group, no difference was seen between healthy controls and PD patients in miR-31 peritoneal membrane expression. However, a trend of up-regulation in miR-31 expression was observed between uremic controls and PD patients (Supplemental Figure S4C).

Previous studies have identified direct targeting by miR-21 of PDCD $4,{ }^{33-35}$ and sequence analysis demonstrated a conserved target site for miR-21 (Supplemental Figure S6). To confirm that this was relevant in the peritoneal membrane in vivo, expression of PDCD4 was examined in samples from the pediatric peritoneal membrane biopsy registry. Peritoneal membrane biopsy specimens from PD patients showed a significant down-regulation in PDCD4 expression in the mesothelial and submesothelial compact zones when compared with controls (Figure 2, E-G). Taken together, these data are consistent with repression of PDCD4 by miR-21 contributing to MMT and promotion of fibrosis in the peritoneal membrane.

\section{miR-21 Expression in PD Effluent Correlates with Clinically Important Parameters}

To assess the potential of miR-21 as a biomarker, miRNA expression was analyzed in patient PDE samples. Initial experiments demonstrated stability of miRNA signal for at least 8 hours after sample collection (data not shown). Subsequently, samples of effluent dialysate after a 4-hour standardized dwell in a cohort of 230 patients recruited to The Global Fluid Study ${ }^{23}$ in a single center were analyzed. Supplemental Table S1 displays baseline clinical characteristics of the patients. When measured in effluent of prevalent PD patients, miR-21 and miR-31 expression levels were strongly increased in comparison with incident cases (fold change: miR-21, 3.26 $\times, P=0.001$; miR-31, 1.84 $\times$, $P=0.0007$ ) (Figure $3 \mathrm{~A}$ and Supplemental Figure S7).

To investigate the relationship between miR-21, miR-31, and parameters associated with poor PD outcome, we performed an exploratory correlation analysis in which miR-21 better correlated with parameters associated with an inflammatory condition (Supplemental Table S2). To understand the relevance of these variables for the described miR21 up-regulation, we performed a multivariable linear regression with backwards-stepwise variable selection for all parameters included in Supplemental Table S2 and miR21 or miR-31 (Table 2 and Supplemental Table S3).

\footnotetext{
Figure 2 miR-21 expression is up-regulated at the peritoneal membrane in peritoneal dialysis patients. Formalin-fixed, paraffin-embedded (FFPE) samples were stained for p-SMAD2/3 (A-C) and PDCD4 (E-G), and manually macrodissected to measure relative expression of miR-21 (D) from a total of 44 patients. A: Histological image analysis using Aperio Precision Image Analysis Software. Mesothelial and submesothelial compact zone selection and p-SMAD2/3 detection of the area of interest by the Aperio positive pixel count algorithm. Negative background (blue), positive p-SMAD2/3 detection (yellow-orange) and border of counted area (colored lines). B: Higher-magnification image to demonstrate nuclear immunostaining of $p$-SMAD2/3 and negative control. C: -SMAD2/3 up-regulation. Level of p-SMAD2/3 staining was defined using a count algorithm for positive pixel detection. D: miR-21 expression. miR-21 expression was analyzed by quantitative RT-PCR and normalized to miR-191 expression. E-G: FFPE samples were PDCD4 stained. E: Histological image analysis using Aperio Precision Image Analysis Software. Mesothelial and submesothelial compact zone was selected as area of interest, and PDCD4 staining was quantified by the Aperio positive pixel count algorithm. F: PDCD4 negative control. G: Positive PDCD4 detection (brown). Data were analyzed by one-way analysis of variance, followed by post hoc Holm-Sidak test comparing all condition means. Data are expressed as means \pm SEM. $n=11$ age-matched samples and equal average PD duration between PD groups $(\mathbf{A}-\mathbf{G}) ; n=44$ total patients $(\mathbf{A}-\mathbf{G}) .{ }^{*} P<0.05, * * * P<0.005$, $* * * * P<0.001$, and $* * * * * P<0.0005$. Scale bars: $300 \mu \mathrm{m}(\mathbf{A}) ; 50 \mu \mathrm{m}(\mathbf{B}) ; 80 \mu \mathrm{m}(\mathbf{F}$ and $\mathbf{G})$.
} 

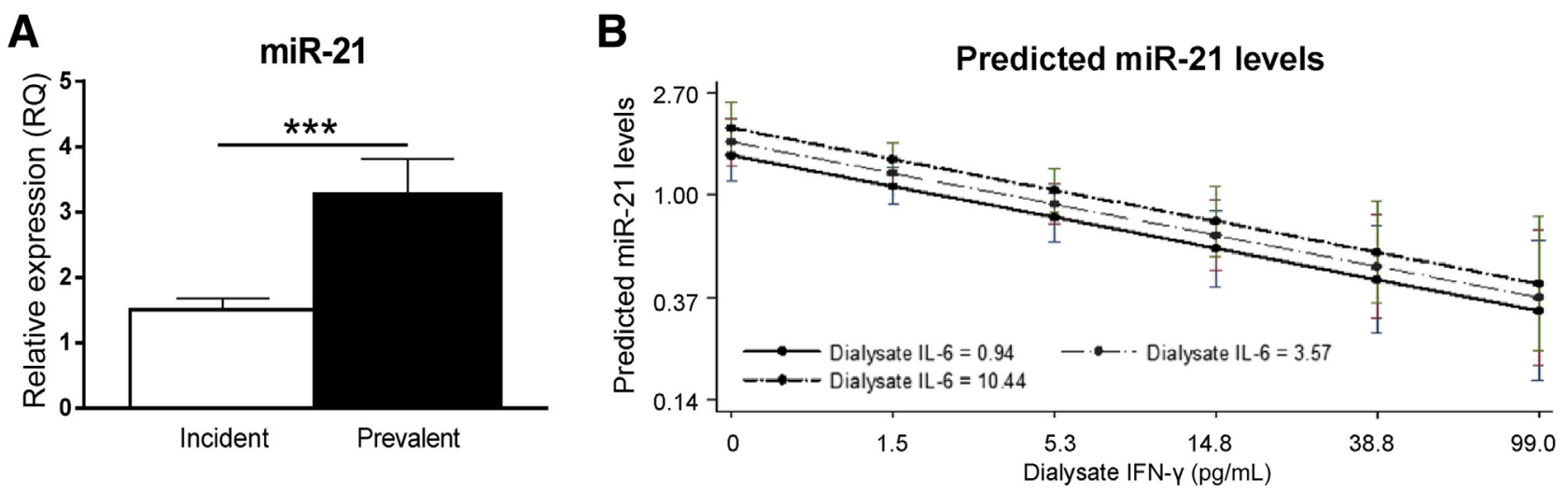

Figure 3 miR-21 expression in peritoneal dialysis effluent (PDE) from PD patients. RNA from 230 PDE samples was isolated, and relative expression of miR-21 was normalized to miR-191 expression. A: Up-regulation of miR-21 expression in PDE from prevalent PD patients compared with incident cases. Data were analyzed by unpaired $U$-test. B: Effect of IL- 6 and interferon (IFN) $-\gamma$ on miR-21 prediction levels. The predicted variable, miR-21, was log transformed. Data are expressed as means \pm SEM. $n=122$ incident patients $(\mathbf{A}) ; n=230(\mathbf{B}) .{ }^{* * *} P<0.005$.

Consequently, stepwise variable selection determined a group of tighter risk factors that associated with miR-21 in predicting PD outcome. miR-21 associated with dialysate icodextrin use ( $R=0.52 ; 95 \% \mathrm{CI}, 0.20-0.84)$, peritonitis count $(R=0.16$; 95\% CI, 0.03-0.29), miR-31 $(R=0.52$; 95\% CI, 0.15-0.90), and dialysate cytokines (Table 2). miR-31 associated with biocompatible solution use ( $R=0.18 ; 95 \% \mathrm{CI},-0.04$ to 0.40$)$, use of continuous ambulatory PD versus ambulatory PD $(R=0.14 ; 95 \% \mathrm{CI}$, $0.02-0.25), \operatorname{miR}-21(R=0.087 ; 95 \% \mathrm{CI}, 0.038-0.136)$, peritonitis count $(R=0.052$; 95\% CI, 0.006-0.098), plasma albumin ( $R=0.0096$; $95 \% \mathrm{CI},-0.001$ to 0.020 ), and urine volume $(R=-0.0001 ; 95 \% \mathrm{CI},-0.00017$ to -0.00003 ) (Supplemental Table S3). Recent work shows that IL-6 and interferon (IFN)- $\gamma$ cooperate to shift acute peritoneal inflammation into a more chronic profibrotic state after recurrent inflammatory episodes. ${ }^{36}$ IL-6 concentration in PD effluent is the most significant known predictor of peritoneal small solute transport rate. ${ }^{23}$ However, IFN- $\gamma$ shows a strong correlation with localized intraperitoneal inflammatory networks. ${ }^{23}$ In the current study, association between miR-21 and IL- 6 was of borderline significance on multivariable linear regression $(R=0.28 ; 95 \% \mathrm{CI},-0.02$ to 0.58 ), whereas dialysate IFN- $\gamma$ was highly significant $(R=-0.77 ; 95 \% \mathrm{CI},-1.21$ to -0.33$)$ when adjusted for dialysate IL-6. Herein, we used values from the range of

Table 2 Multivariable Regression of miR-21

\begin{tabular}{lcl}
\hline Variable & Coefficient $(95 \%$ CI $)$ & $P$ value \\
\hline Icodextrin use & $0.52(0.20-0.84)$ & 0.002 \\
Peritonitis count & $0.16(0.03-0.29)$ & 0.015 \\
Dialysate IL-6 & $0.28(-0.02$ to 0.58$)$ & 0.065 \\
Dialysate TNF- $\alpha$ & $0.86(-0.61$ to 2.34$)$ & 0.25 \\
Dialysate IFN- $\gamma$ & $-0.77(-1.21$ to -0.33$)$ & 0.001 \\
Dialysate IL-1 $\beta$ & $0.69(-0.89$ to 2.27$)$ & 0.39 \\
Body mass index & $0.027(-0.0004$ to 0.054$)$ & 0.053 \\
\hline
\end{tabular}

Multivariable linear regression with backwards stepwise variable selection for parameters listed in Supplemental Table S2.

IFN- $\gamma$, interferon- $\gamma$; TNF- $\alpha$, tumor necrosis factor- $\alpha$. dialysate IFN- $\gamma$ stratified by the $25^{\text {th }}, 50^{\text {th }}$, and $75^{\text {th }}$ centiles for dialysate IL- 6 and showed strong prediction of miR-21 expression (Figure 3B).

\section{Identification of miR-21 Targets that May Contribute to MMT during PD Therapy}

PDCD4 is an important effector of miR-21-induced fibrotic change in other contexts, and herein we have found PDCD4 to be down-regulated in the peritoneal membrane of patients treated with PD (Figure 2, E-G). However, miRNAs typically have several hundred targets and may be predicted to control changes in cell phenotype via broad actions across many targets. To have a more complete understanding of how miR-21 up-regulation may lead to MMT and fibrosis in the peritoneal membrane, predicted miR-21 targets were evaluated in an Affymetrix array data set comprising profiles of control, early MMT, and late MMT, using patientderived effluent mesothelial cells cultured ex vivo, as previously described. ${ }^{4}$ Overall, 774 genes were identified as down-regulated in the MMT process, including 274 transcripts identified as down-regulated specifically in early MMT and 298 transcripts in late MMT (Figure 4A). Independent miR-21 target prediction was undertaken using four different algorithms, and results subsequently combined, comprising DIANA (http://diana.imis.athena-innovation.gr/ DianaTools/index.php), ${ }^{37,38}$ miRDB (http://mirdb.org), ${ }^{39,40}$ miRanda (http://www.microrna.org/microrna/home.do), ${ }^{41,42}$ and TargetScan (http://www.targetscan.org/vert_71) ${ }^{43,44}$ (Figure 4B). Single miR-21 algorithm predictions were intercrossed to identify targets that were predicted by three or more algorithms (Figure 4B). These predicted miR-21 targets were further intercrossed with the genes identified as downregulated in MMT (Figure 4C). Five miR-21-predicted targets were identified to be differentially down-regulated during early MMT, two in the late MMT course, and 10 when the whole MMT was evaluated (Figure $4 \mathrm{C}$ ). These included the following: early MMT, natriuretic peptide B (NPPB), PDZD2, 
A

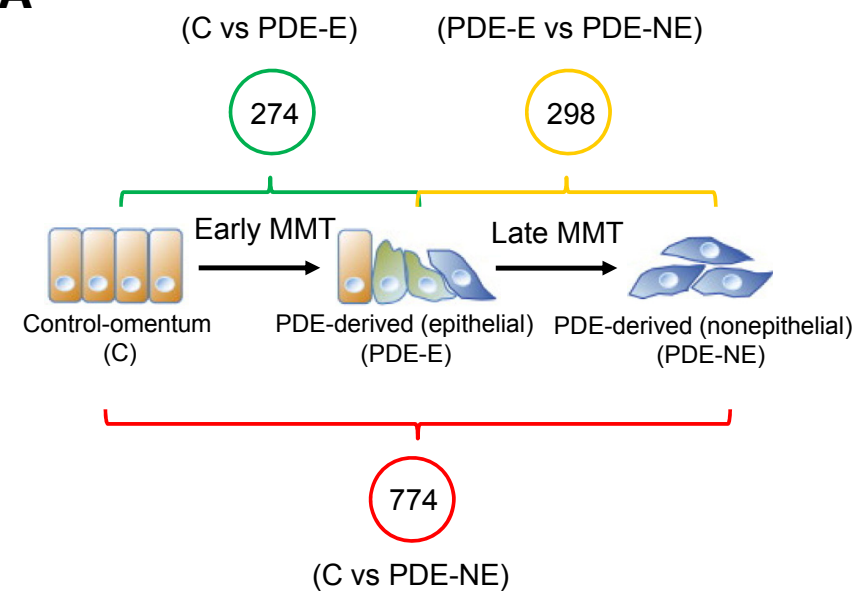

B

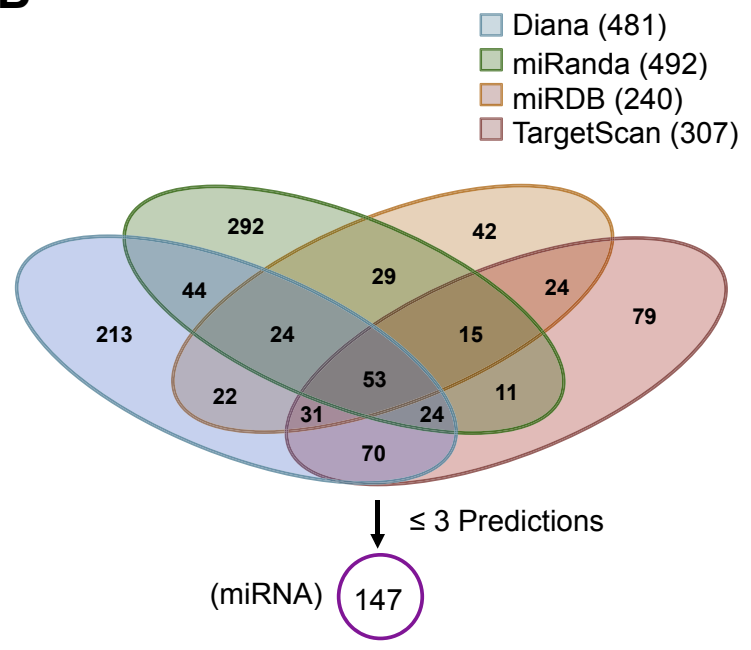

C

(miRNA vs C-PDE-E)

(miRNA vs PDE-E-PDE-NE)

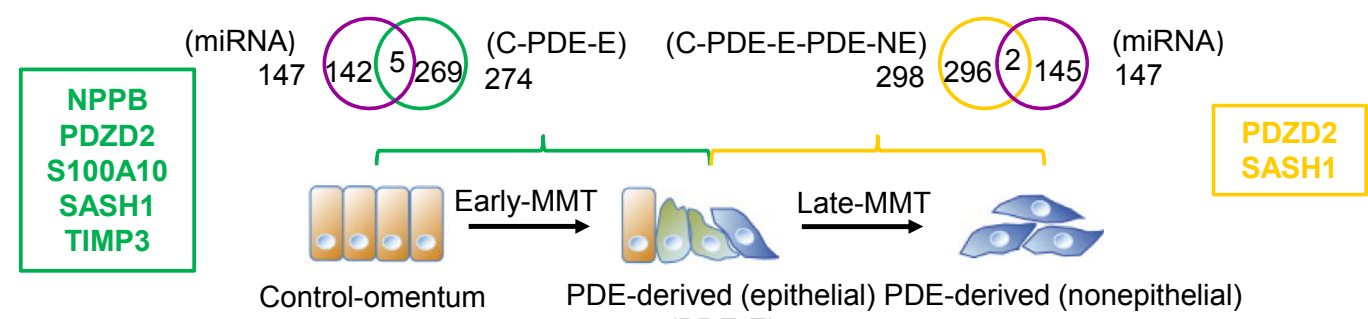

(C) (PDE-E)

\begin{tabular}{|cc|}
\hline AIM1L & NELL2 \\
CASKIN1 & PDZD2 \\
DUSP8 & RHOB \\
FGF18 & SASH1 \\
MATN2 & SPRY1 \\
\hline
\end{tabular}

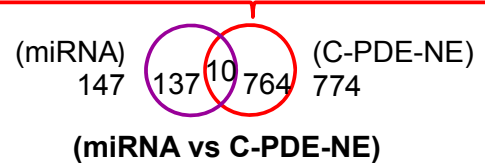

(PDE-NE)

Figure 4 Mesothelial-to-mesenchymal mRNA array changes associated with PD therapy in HPMCs and in silico target prediction to identify new miR-21 targets that may contribute to the process. A: Diagram displaying mRNA array changes comparing control omentum HPMCs and PDE-derived MCs with epithelial phenotype (early MMT, green), PDE-derived MCs with epithelial phenotype and nonepithelial phenotype (late MMT, yellow), and control omentum HPMCs and PDE-derived MCs with nonepithelial phenotype (whole MMT, red). B: miR-21 target prediction using Diana (blue), miRDB (brown), miRanda (green), and TargetScan (red) intercrossed using Venn diagram to identify targets that were predicted by three or more algorithms. C: Diagram displaying miR-21 targets predicted and identified in B further intercrossed using Venn diagram with the mRNA array changes identified in A (green, yellow, red). Common targets identified by $\mathbf{A}$ and B intercrossed lists are shown in squares with the respective MMT color (top left, early MMT; top right, late MMT; bottom, whole MMT).

S100 calcium-binding protein A10 (S100A10), SAM and SH3 domain containing 1 ( $S A S H 1)$, and metalloproteinase inhibitor 3 (TIMP3); late MMT, PDZD2 and SASH1; and whole MMT, absent in melanoma 1-like (AIMIL), CASK interacting protein 1 (CASKINI), dual specificity phosphatase 8 (DUSP8), fibroblast growth factor 18 (FGF-18), matrilin 2 (MATN2), neural EGFL like 2 (NELL2), PDZD2 [Ras homolog family member B (RHOB), SASH1, and Sprouty RTK signaling antagonist 1 (SPRY1)].

\section{Evaluation of miR-21 Targets in HPMCs under MMT Conditions}

The above analysis provided 14 predicted miR-21 targets identified as down-regulated in ex vivo cultured mesothelial cells exhibiting MMT. These 14 genes were subsequently examined by RT-qPCR in mesothelial cells exhibiting progressively more mesenchymal phenotype (control, incubated with TGF- $\beta 1$, effluent-derived epithelioid, effluent-derived nonepithelioid). Of 14 genes, 11 demonstrated a pattern of expression consistent with miR-21 regulation in this model (Figure 5 and Supplemental Figure S8). mirVana miR-21 mimic and inhibitor delivery in HPMCs was used to evaluate these 11 predicted targets. Five targets showed significant down-regulation by miR-21 mimic and up-regulation by inhibitor (namely, PDZD2, S100A10, FGF-18, MATN2, and PDCD4) (Figure 6). CASKIN1, NELL2, and DUSP8 were up-regulated by miR21 inhibitor but did not show significant change in response to enforced expression of miR-21, and SASH1 and AIM1L 
A

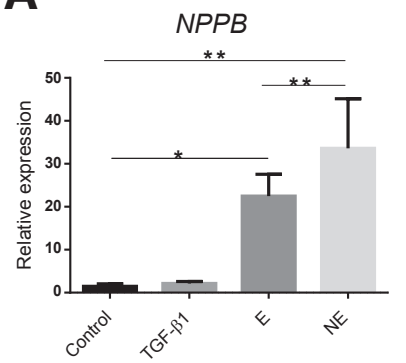

E

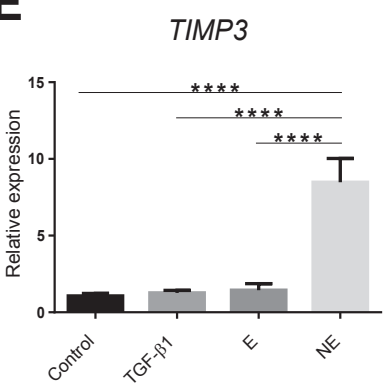

I

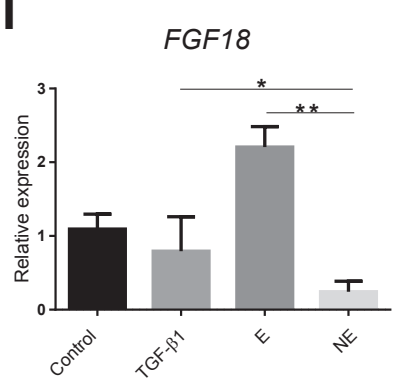

M

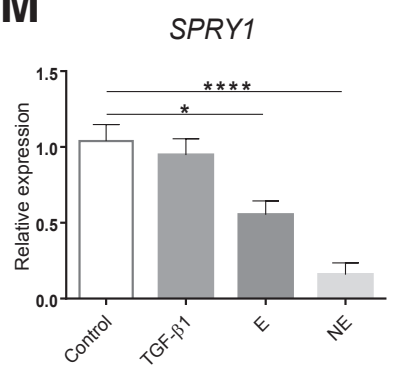

B

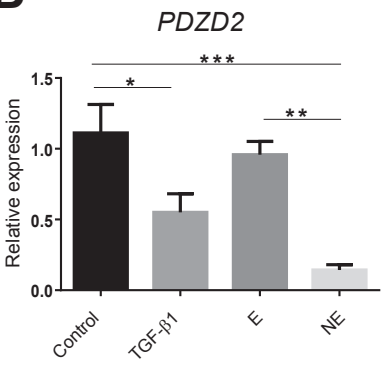

F

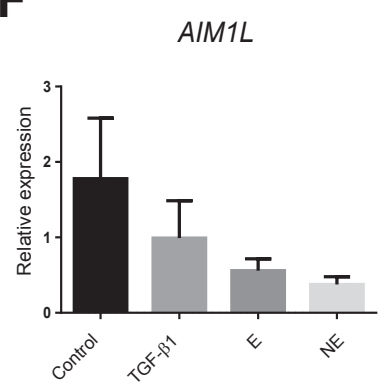

J

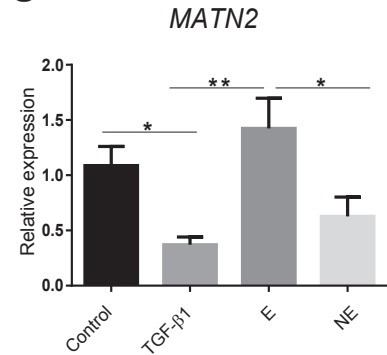

N

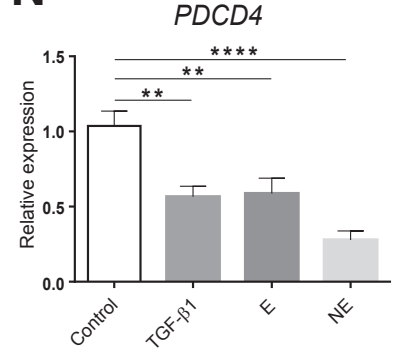

C

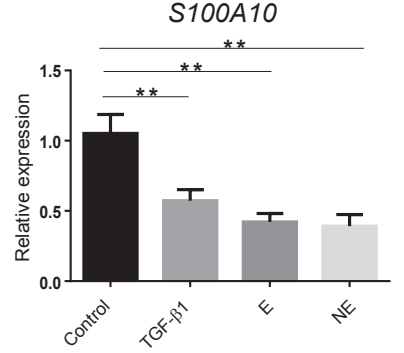

G

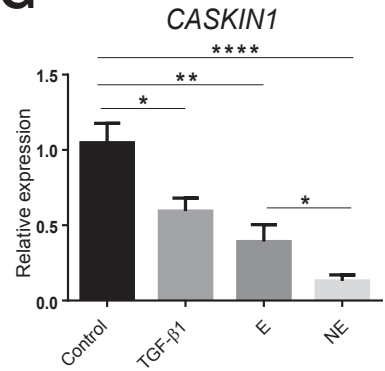

K

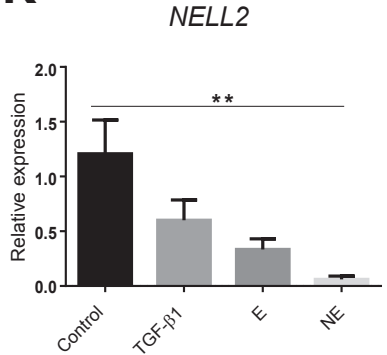

D

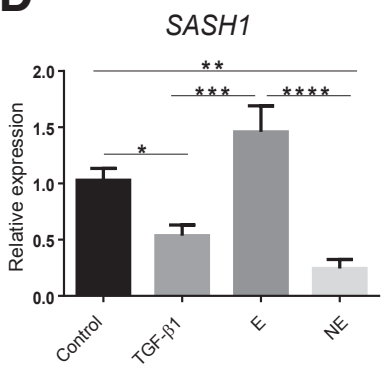

H

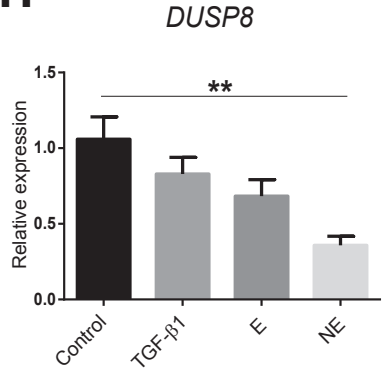

L

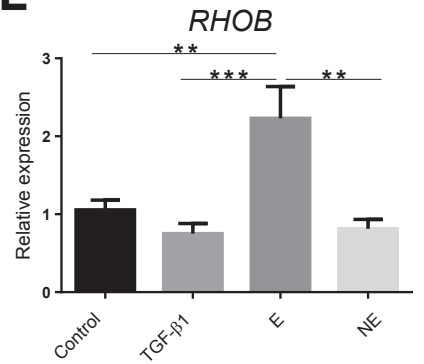

Figure 5 Predicted miR-21 target profiling in a model of progressive peritoneal membrane deterioration. A-N: Relative mRNA expression in control omentum-derived mesothelial cells (HPMCs), $1 \mathrm{ng} / \mathrm{mL}$ TGF- $\beta 1$ treated (48 hours) and cultured peritoneal effluent-derived (PDE) cells with epithelial (E) and nonepithelial (NE) phenotype. A: NPPB. B: PDZD2. C: S100A10. D: SASH1. E: TIMP3. F: AIM1L. G: CASKIN1. H: DUSP8. I: FGF18. J: MATN2. K: NELL2. L: RHOB. M: SPRY1. N: PDCD4. A-N: Target gene expression was analyzed by quantitative RT-PCR and normalized to glyceraldehyde-3-phosphate dehydrogenase. Data were analyzed by no matched one-way analysis of variance, followed by post hoc Holm-Sidak test. Data are expressed as means \pm SEM. $n=5$ independent donor experiments $(\mathbf{A}-\mathbf{N}) .{ }^{*} P<0.05,{ }^{*} P P<0.01,{ }^{* *} P<0.005$, and $* * * * P<0.001$.

identified were highly conserved and energetically favorable ( 8 mer or 7 mer-m8 sites ${ }^{45}$ ), in keeping with direct regulation of these targets.

\section{Discussion}

PD is an effective form of renal replacement therapy, but is often limited by deterioration in the structural and functional characteristics of the peritoneal membrane. New biomarkers 
A

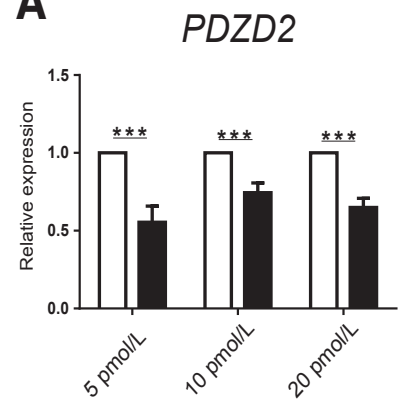

E

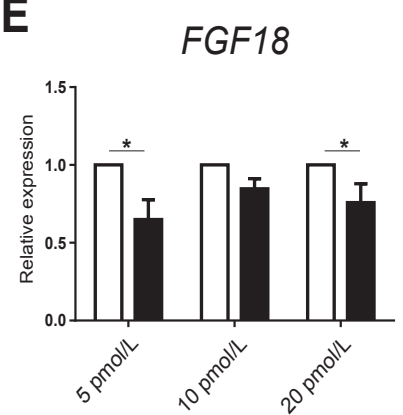

I

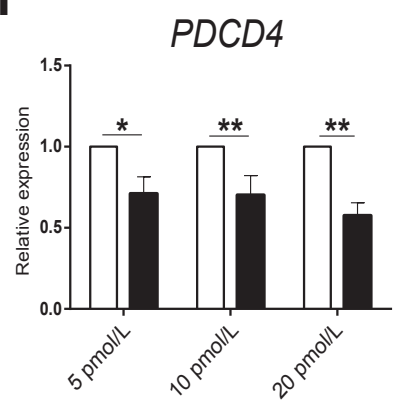

B

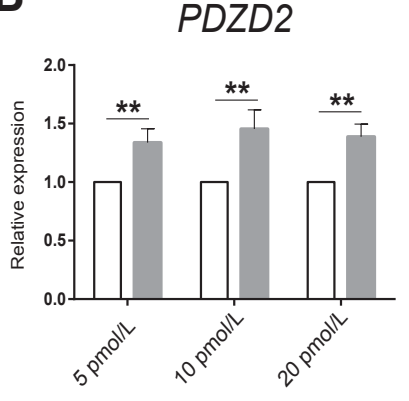

$\mathbf{F}$

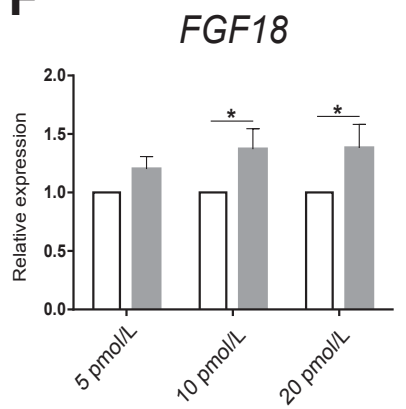

J

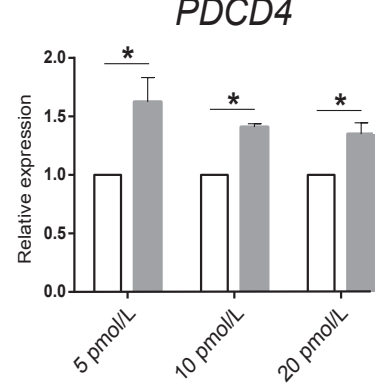

C

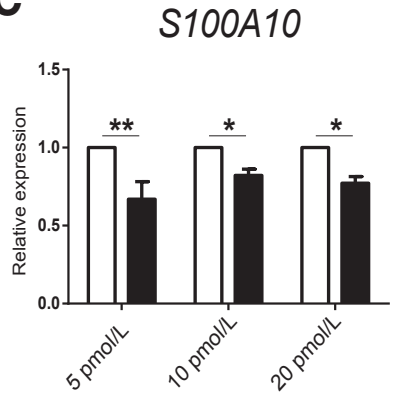

G

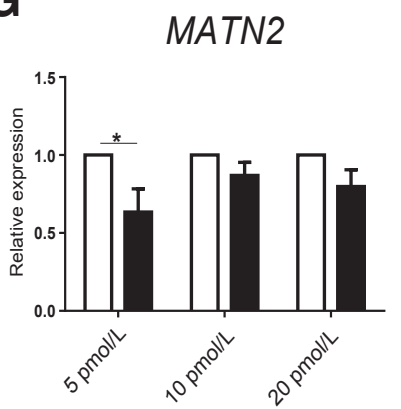

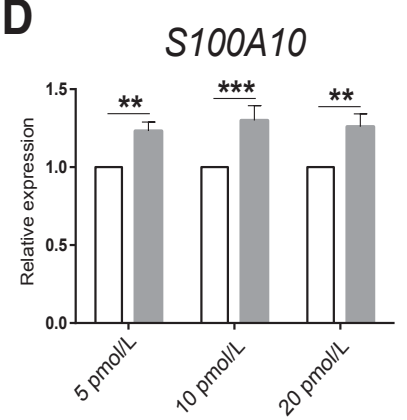

H

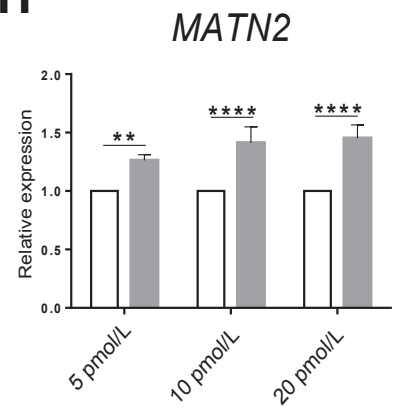

Figure 6 miR-21 target mRNA expression 48 hours after miRNA mimic (A, C, E, G, and $\mathbf{I})$ or inhibitor (B, D, F, H, and $\mathbf{J})$ delivery in HPMCs at concentrations of 5 to $20 \mathrm{pmol} / \mathrm{L}$, as indicated. miRNAcontrol (mimic or inhibitor) is indicated by white bars; miR-21 mimic, black bars; miR-21 inhibitor, gray bars. A and B: PDZD2. C and D: S100A10. E and F: FGF18. G and H: MATN2. I and J: PDCD4. Target gene expression was analyzed by quantitative RT-PCR and normalized to GAPDH expression. Data were analyzed by matched factor two-way analysis of variance, followed by post hoc HolmSidak test. Data are expressed as means \pm SEM. $n=3$ miRNA mimic independent donor experiments $(\mathbf{A}-\mathbf{J}) ; n=6$ miRNA inhibitor independent donor experiments $(\mathbf{A}-\mathbf{J})$. ${ }^{*} P<0.05$, ${ }^{* *} P<0.01,{ }^{* * *} P<0.005$, and ${ }^{* * * *} P<0.001$.

to TGF- $\beta 1$. These data showed abundant expression of miR21 in mesothelial cells, and increased expression when cells were incubated with TGF- $\beta 1$. Previous studies have characterized the phenotype of mesothelial cells isolated from PDE from patients and demonstrated that a progressive loss of epithelial morphology is accompanied by a decrease of cytokeratins and E-cadherin expression as well as an induction of the transcriptional repressor Snail. ${ }^{4}$ Further experiments found increased miR-21 in PDE-derived mesothelial cells with these mesenchymal characteristics, linking miR-21 to mesothelial cell characteristics previously shown to define an adverse response to PD. ${ }^{4}$

Subsequently, miR-21 expression was examined in peritoneal membrane biopsy specimens. Fibroproliferative changes have been delineated in the peritoneal membrane of PD patients, together with more minor changes in uremic (predialysis) patients. ${ }^{47}$ Peritoneal vascular changes are also frequently evident in adult patients, which may make it difficult to separate therapy-induced alterations from those related to the propensity of individuals with chronic kidney 
disease to accelerated cardiovascular disease. At the time of PD onset, the pediatric peritoneal tissue is devoid of vascular alterations and tissue aging. To determine the pure effects of the therapy, pediatric biopsy samples were examined, from the International Pediatric Peritoneal Biopsy Registry. TGF$\beta 1$ signaling was clearly evident in biopsy specimens from PD patients compared to controls, and was associated with increased miR-21 and decreased PDCD4 in the mesothelial and submesothelial zones. Given recent fate mapping studies, which have delineated an important contribution of submesothelial fibroblasts to peritoneal fibrosis in mouse models, ${ }^{5}$ understanding the potential role of miRNAs, including miR-21, in submesothelial fibroblast phenotype may also be an important future area of study.

Inflammatory markers, most notably Il-6, may be measured in the dialysis effluent as an indirect measure of intraperitoneal inflammation, ${ }^{48}$ although a biomarker for the extent of peritoneal fibrosis is still lacking. Multivariable linear regression with backwards-stepwise variable selection was performed, to understand associations of miR-21 expression with clinical characteristics and measures of intraperitoneal inflammation. Of note, miR-21 correlated with icodextrin use, which has been previously associated with multiple indicators of local inflammation. ${ }^{23,49}$ The relationship between intraperitoneal inflammation and membrane function has also been recently investigated in PD patients. ${ }^{23,50}$ In the current study, we also found miR-21 association with peritonitis count and dialysate IFN- $\gamma$, IL-6, tumor necrosis factor- $\alpha$, and IL-1 $\beta$, suggesting a primary response to local factors and inflammatory stimuli. IFN $-\gamma,{ }^{51}$ tumor necrosis factor- $\alpha$, and IL- $1 \beta^{52}$ induce IL- 6 secretion by mesothelial cells, the major producers of IL- 6 within the peritoneal cavity. ${ }^{52,53} \mathrm{IL}-6$, in turn, is also an important inducer of miR-21 in multiple myeloma, mammary epithelium, hepatocellular carcinoma, oral squamous cell carcinoma, and keratinocytes via STAT signaling, ${ }^{54-58}$ providing a potential mechanistic basis for the association of proinflammatory cytokines with miR-21 expression in the context of peritoneal dialysis.

Herein, we identified miR-21-mediated repression of PDCD4 in mesothelial cells. PDCD4 down-regulation triggers an increase in SNAIL protein and a consequent decrease in E-cadherin expression, which, in turn, stimulates $\beta$-catenin dependent transcription. ${ }^{33-35}$ Thus, miR-21 down-regulation of PDCD4 in HPMCs may not only contribute to the detachment of intermesothelial adhesions but also to the acquisition of a new molecular program, dictating a distinct expression regulation characteristic of an MMT process. In addition, we identified four new miR-21 targets that may be important in the context of PD therapy-associated fibrogenesis (PDZD2, S100A10, FGF-18, and MATN2). Previous literature has linked a reduction of expression of these genes with fibrosis in different contexts. In brief, mice with conditional deletion of FGF-18 in the lung displayed thicker interstitial mesenchymal compartments, embedded capillaries, and reduced cell proliferation, ${ }^{59}$ whereas FGF-18 overexpression in lung decreased extracellular matrix and connective tissue components, including matrilin-2. ${ }^{60}$ Between the multiple functions attributed to S100A10, probably the most physiologically remarkable is its extracellular function as a plasminogen receptor, mediating its activation by plasminogen activators, stimulating plasminogen conversion to wide protease plasmin, and promoting fibrinolysis. ${ }^{61}$ Indeed, S100A10-null mice, although viable, showed impaired fibrinolysis and increased tissue fibrin deposition, including in lungs, liver, spleen, and kidney, compared to wild-type mice litter mates. ${ }^{61}$ Matrilin-2 binds collagen I and noncollagenous proteins, ${ }^{62}$ contributing to extracellular matrix supramolecular organization. Matrilin-2 knockdown induced serious defects in skin wound healing. ${ }^{63}$ In addition, Ichikawa et $\mathrm{al}^{63}$ showed that matrilin-2 reduction in human keratinocyte cells induced cell migration into a wound. In vitro treatment with recombinant sPDZD2 induces p53 up-regulation in human prostate cancer (DU-145), breast adenocarcinoma (MCF-7), and liver cancer (Hep-G2) cell lines, ${ }^{64}$ and such altered p53 activity may inhibit epithelial-mesenchymal transition. ${ }^{65}$ More important, though, PDZD2 is expressed in the nucleus and also secreted after cleavage, ${ }^{66}$ suggesting a potentially complex role in these processes.

In PD patients, continuous dialysis fluid exchanges allow easy access to monitor peritoneal miRNA expression. Previous studies have demonstrated that Il- 6 and IFN- $\gamma$ are strong predictors of MC damage in PD patients, and are mechanistically linked to peritoneal fibrosis after infection. ${ }^{36}$ Nevertheless, no biomarker or combination of biomarkers yet allows prediction of outcome for the single patient or individualized therapy. In this study, miRNAs were found to be stable and readily detected in the peritoneal dialysis effluent, emphasizing their potential as a class of biomarker in this context. miR-21 was found to be up-regulated in mesothelial cells undergoing MMT, and in peritoneal membrane undergoing fibrosis in the context of PD. miR-21 was further found to be stable in dialysis effluent, and PD effluent levels were found to correlate with different clinically important parameters themselves linked to membrane change in this patient group. These data identify miR-21 as a promising biomarker to monitor the peritoneal membrane of patients undergoing PD therapy.

\section{Acknowledgments}

We thank the staff of National Center for Tumor Diseases (Heidelberg, Germany) and Institute of Pathology (Heidelberg University Hospital) for technical assistance.

\section{Supplemental Data}

Supplemental material for this article can be found at http://dx.doi.org/10.1016/j.ajpath.2017.03.007. 


\section{References}

1. Aroeira LS, Aguilera A, Sánchez-Tomero JA, Bajo MA, del Peso G, Jiménez-Heffernan JA, Selgas R, López-Cabrera M: Epithelial to mesenchymal transition and peritoneal membrane failure in peritoneal dialysis patients: pathologic significance and potential therapeutic interventions. J Am Soc Nephrol 2007, 18:2004-2013

2. Yu JW, Duan WJ, Huang XR, Meng XM, Yu XQ, Lan HY: MicroRNA-29b inhibits peritoneal fibrosis in a mouse model of peritoneal dialysis. Lab Invest 2014, 94:978-990

3. Loureiro J, Aguilera A, Selgas R, Sandoval P, Albar-Vizcaíno P, Pérez-Lozano ML, Ruiz-Carpio V, Majano PL, Lamas S, RodríguezPascual F, Borras-Cuesta F, Dotor J, López-Cabrera M: Blocking TGF- $\beta 1$ protects the peritoneal membrane from dialysate-induced damage. J Am Soc Nephrol 2011, 22:1682-1695

4. Yáñez-Mó M, Lara-Pezzi E, Selgas R, Ramírez-Huesca M, Domínguez-Jiménez C, Jiménez-Heffernan JA, Aguilera A, SánchezTomero JA, Bajo MA, Alvarez V, Castro MA, del Peso G, Cirujeda A, Gamallo C, Sánchez-Madrid F, López-Cabrera M: Peritoneal dialysis and epithelial-to-mesenchymal transition of mesothelial cells. N Engl J Med 2003, 348:403-413

5. Chen YT, Chang YT, Pan SY, Chou YH, Chang FC, Yeh PY, Liu YH, Chiang WC, Chen YM, Wu KD, Tsai TJ, Duffield JS, Lin SL: Lineage tracing reveals distinctive fates for mesothelial cells and submesothelial fibroblasts during peritoneal injury. J Am Soc Nephrol 2014, 25:2847-2858

6. Bowen T, Jenkins RH, Fraser DJ: MicroRNAs, transforming growth factor beta-1, and tissue fibrosis. J Pathol 2013, 229:274-285

7. Margetts PJ, Bonniaud P, Liu L, Hoff CM, Holmes CJ, West-Mays JA, Kelly MM: Transient overexpression of TGF- $\{$ beta 11 induces epithelial mesenchymal transition in the rodent peritoneum. J Am Soc Nephrol 2005, 16:425-436

8. Margetts PJ, Kolb M, Galt T, Hoff CM, Shockley TR, Gauldie J: Gene transfer of transforming growth factor-betal to the rat peritoneum: effects on membrane function. J Am Soc Nephrol 2001, 12:2029-2039

9. Selgas R, Bajo A, Jiménez-Heffernan JA, Sánchez-Tomero JA, Del Peso G, Aguilera A, López-Cabrera M: Epithelial-to-mesenchymal transition of the mesothelial cell: its role in the response of the peritoneum to dialysis. Nephrol Dial Transplant 2006, 21(Suppl 2):ii2-ii7

10. Landgraf P, Rusu M, Sheridan R, Sewer A, Iovino N, Aravin A, et al: A mammalian microRNA expression atlas based on small RNA library sequencing. Cell 2007, 129:1401-1414

11. Brown BD, Naldini L: Exploiting and antagonizing microRNA regulation for therapeutic and experimental applications. Nat Rev Genet 2009, 10:578-585

12. Cortez MA, Bueso-Ramos C, Ferdin J, Lopez-Berestein G, Sood AK, Calin GA: MicroRNAs in body fluids: the mix of hormones and biomarkers. Nat Rev Clin Oncol 2011, 8:467-477

13. Kota J, Chivukula RR, O'Donnell KA, Wentzel EA, Montgomery CL, Hwang HW, Chang TC, Vivekanandan P, Torbenson M, Clark KR, Mendell JR, Mendell JT: Therapeutic microRNA delivery suppresses tumorigenesis in a murine liver cancer model. Cell 2009, 137:1005-1017

14. Turchinovich A, Weiz L, Langheinz A, Burwinkel B: Characterization of extracellular circulating microRNA. Nucleic Acids Res 2011, 39:7223-7233

15. Lopez-Anton M, Bowen T, Jenkins HR: microRNA regulation of peritoneal cavity homeostasis in peritoneal dialysis. Biomed Res Int 2015, 2015:929806

16. Chen J, Kam-Tao P, Kwan BC, Chow KM, Lai KB, Luk CC, Szeto CC: Relation between microRNA expression in peritoneal dialysis effluent and peritoneal transport characteristics. Dis Markers 2012, 33:35-42

17. Zhou Q, Yang M, Lan H, Yu X: miR-30a negatively regulates TGF$\beta 1$-induced epithelial-mesenchymal transition and peritoneal fibrosis by targeting Snai1. Am J Pathol 2013, 183:808-819
18. Ohkubo T, Ozawa M: The transcription factor Snail downregulates the tight junction components independently of E-cadherin downregulation. J Cell Sci 2004, 117:1675-1685

19. Kurrey NK, Amit K, Bapat SA: Snail and Slug are major determinants of ovarian cancer invasiveness at the transcription level. Gynecol Oncol 2005, 97:155-165

20. Zhang K, Zhang H, Zhou X, Tang WB, Xiao L, Liu YH, Liu H, Peng YM, Sun L, Liu FY: miRNA589 regulates epithelialmesenchymal transition in human peritoneal mesothelial cells. J Biomed Biotechnol 2012, 2012:673096

21. Zhang L, Liu F, Peng Y, Sun L, Chen G: Changes in expression of four molecular marker proteins and one microRNA in mesothelial cells of the peritoneal dialysate effluent fluid of peritoneal dialysis patients. Exp Ther Med 2013, 6:1189-1193

22. Stylianou E, Jenner LA, Davies M, Coles GA, Williams JD: Isolation, culture and characterization of human peritoneal mesothelial cells. Kidney Int 1990, 37:1563-1570

23. Lambie M, Chess J, Donovan KL, Kim YL, Do JY, Lee HB, Noh H, Williams PF, Williams AJ, Davison S, Dorval M, Summers A, Williams JD, Bankart J, Davies SJ, Topley N; Global Fluid Study Investigators: Independent effects of systemic and peritoneal inflammation on peritoneal dialysis survival. J Am Soc Nephrol 2013, 24:2071-2080

24. Peltier HJ, Latham GJ: Normalization of microRNA expression levels in quantitative RT-PCR assays: identification of suitable reference RNA targets in normal and cancerous human solid tissues. RNA 2008, 14:844-852

25. Livak KJ, Schmittgen TD: Analysis of relative gene expression data using real-time quantitative PCR and the 2(-Delta Delta $\mathrm{C}(\mathrm{T})$ ) Method. Methods 2001, 25:402-408

26. Jang YH, Shin HS, Sun Choi H, Ryu ES, Jin Kim M, Ki Min S, Lee JH, Kook Lee H, Kim KH, Kang DH: Effects of dexamethasone on the TGF- $\beta 1$-induced epithelial-to-mesenchymal transition in human peritoneal mesothelial cells. Lab Invest 2013, 93:194-206

27. Xiao L, Peng X, Liu F, Tang C, Hu C, Xu X, Wang M, Luo Y, Yang S, Song P, Xiao P, Kanwar YS, Sun L: AKT regulation of mesothelial-tomesenchymal transition in peritoneal dialysis is modulated by Smurf2 and deubiquitinating enzyme USP4. BMC Cell Biol 2015, 16:7

28. Xiao L, Zhou X, Liu F, Hu C, Zhu X, Luo Y, Wang M, Xu X, Yang S, Kanwar YS, Sun L: MicroRNA-129-5p modulates epithelialto-mesenchymal transition by targeting SIP1 and SOX4 during peritoneal dialysis. Lab Invest 2015, 95:817-832

29. Ruiz-Carpio V, Sandoval P, Aguilera A, Albar-Vizcaíno P, PerezLozano ML, González-Mateo GT, Acuña-Ruiz A, García-Cantalejo J, Botías P, Bajo MA, Selgas R, Sánchez-Tomero JA, Passlick-Deetjen J, Piecha D, Büchel J, Steppan S, López-Cabrera M: Genomic reprograming analysis of the mesothelial to mesenchymal transition identifies biomarkers in peritoneal dialysis patients. Sci Rep 2017, 7:44941

30. Jenkins RH, Davies LC, Taylor PR, Akiyama H, Cumbes B, Beltrami C, Carrington CP, Phillips AO, Bowen T, Fraser DJ: miR192 induces G2/M growth arrest in aristolochic acid nephropathy. Am J Pathol 2014, 184:996-1009

31. Heller F, Lindenmeyer MT, Cohen CD, Brandt U, Draganovici D, Fischereder M, Kretzler M, Anders HJ, Sitter T, Mosberger I, Kerjaschki D, Regele H, Schlöndorff D, Segerer S: The contribution of B cells to renal interstitial inflammation. Am J Pathol 2007, 170:457-468

32. Medina I, Carbonell J, Pulido L, Madeira SC, Goetz S, Conesa A, Tárraga J, Pascual-Montano A, Nogales-Cadenas R, Santoyo J, García F, Marbà M, Montaner D, Dopazo J: Babelomics: an integrative platform for the analysis of transcriptomics, proteomics and genomic data with advanced functional profiling. Nucleic Acids Res 2010, 38:W210-W213

33. Asangani IA, Rasheed SAK, Nikolova DA, Leupold JH, Colburn NH, Post S, Allgayer H: MicroRNA-21 (miR-21) posttranscriptionally downregulates tumor suppressor Pdcd4 and stimulates invasion, intravasation and metastasis in colorectal cancer. Oncogene 2008, 27:2128-2136 
34. Yao Q, Cao S, Li C, Mengesha A, Kong B, Wei M: Micro-RNA-21 regulates TGF- $\beta$-induced myofibroblast differentiation by targeting PDCD4 in tumor-stroma interaction. Int J Cancer 2011, 128: $1783-1792$

35. Brønnum H, Andersen DC, Schneider M, Sandberg MB, Eskildsen T, Nielsen SB, Kalluri R, Sheikh SP: miR-21 promotes fibrogenic epithelial-to-mesenchymal transition of epicardial mesothelial cells involving Programmed Cell Death 4 and Sprouty-1. PLoS One 2013, 8:e56280

36. Fielding CA, Jones GW, McLoughlin RM, McLeod L, Hammond VJ, Uceda J, Williams AS, Lambie M, Foster TL, Liao CT, Rice CM, Greenhill CJ, Colmont CS, Hams E, Coles B, Kift-Morgan A, Newton Z, Craig KJ, Williams JD, Williams GT, Davies SJ, Humphreys IR, O'Donnell VB, Taylor PR, Jenkins BJ, Topley N, Jones SA: Interleukin-6 signaling drives fibrosis in unresolved inflammation. Immunity 2014, 40:40-50

37. Paraskevopoulou MD, Georgakilas G, Kostoulas N, Vlachos IS, Vergoulis T, Reczko M, Filippidis C, Dalamagas T, Hatzigeorgiou AG: DIANA-microT web server v5.0: service integration into miRNA functional analysis workflows. Nucleic Acids Res 2013, 41:W169-W173

38. Reczko M, Maragkakis M, Alexiou P, Grosse I, Hatzigeorgiou AG: Functional microRNA targets in protein coding sequences. Bioinformatics 2012, 28:771-776

39. Wong N, Wang X: miRDB: an online resource for microRNA target prediction and functional annotations. Nucleic Acids Res 2015, 43: D146-D152

40. Wang X, El Naqa IM: Prediction of both conserved and nonconserved microRNA targets in animals. Bioinformatics 2008, 24:325-332

41. Betel D, Koppal A, Agius P, Sander C, Leslie C: Comprehensive modeling of microRNA targets predicts functional non-conserved and non-canonical sites. Genome Biol 2010, 11:R90

42. Betel D, Wilson M, Gabow A, Marks DS, Sander C: The microRNA.org resource: targets and expression. Nucleic Acids Res 2008, 36:D149-D153

43. Agarwal V, Bell GW, Nam JW, Bartel DP: Predicting effective microRNA target sites in mammalian mRNAs. Elife 2015, 4:e05005. doi:10.7554/eLife.05005

44. Nam JW, Rissland OS, Koppstein D, Abreu-Goodger C, Jan CH, Agarwal V, Yildirim MA, Rodriguez A, Bartel DP: Global analyses of the effect of different cellular contexts on microRNA targeting. Mol Cell 2014, 53:1031-1043

45. Bartel DP: MicroRNAs: target recognition and regulatory functions. Cell 2009, 136:215-233

46. Beltrami C, Clayton A, Phillips AO, Fraser DJ, Bowen T: Analysis of urinary microRNAs in chronic kidney disease. Biochem Soc Trans 2012, 40:875-879

47. Williams JD, Craig KJ, Topley N, Von Ruhland C, Fallon M, Newman GR, Mackenzie RK, Williams GT; Peritoneal Biopsy Study Group: Morphologic changes in the peritoneal membrane of patients with renal disease. J Am Soc Nephrol 2002, 13:470-479

48. Lopes Barreto D, Krediet RT: Current status and practical use of effluent biomarkers in peritoneal dialysis patients. Am J Kidney Dis 2013, 62:823-833

49. Moriishi M, Kawanishi H: Icodextrin and intraperitoneal inflammation. Perit Dial Int 2008, 28(Suppl 3):S96-S100

50. Velloso MS, Otoni A, de Paula Sabino A, de Castro WV, Pinto SW, Marinho MA, Rios DR: Peritoneal dialysis and inflammation. Clin Chim Acta 2014, 430:109-114

51. McLoughlin RM, Witowski J, Robson RL, Wilkinson TS, Hurst SM, Williams AS, Williams JD, Rose-John S, Jones SA, Topley N: Interplay between IFN-gamma and IL-6 signaling governs neutrophil trafficking and apoptosis during acute inflammation. J Clin Invest 2003, 112:598-607

52. Topley N, Jörres A, Luttmann W, Petersen MM, Lang MJ, Thierauch KH, Müller C, Coles GA, Davies M, Williams JD: Human peritoneal mesothelial cells synthesize interleukin-6: induction by IL1 beta and TNF alpha. Kidney Int 1993, 43:226-233

53. Witowski J, Jörres A, Coles GA, Williams JD, Topley N: Superinduction of IL-6 synthesis in human peritoneal mesothelial cells is related to the induction and stabilization of IL-6 mRNA. Kidney Int 1996, 50:1212-1223

54. Löffler D, Brocke-Heidrich K, Pfeifer G, Stocsits C, Hackermüller J, Kretzschmar AK, Burger R, Gramatzki M, Blumert C, Bauer K, Cvijic H, Ullmann AK, Stadler PF, Horn F: Interleukin-6 dependent survival of multiple myeloma cells involves the Stat3-mediated induction of microRNA-21 through a highly conserved enhancer. Blood 2007, 110:1330-1333

55. Lu X, Luo F, Liu Y, Zhang A, Li J, Wang B, Xu W, Shi L, Liu X, Lu L, Liu Q: The IL-6/STAT3 pathway via miR-21 is involved in the neoplastic and metastatic properties of arsenite-transformed human keratinocytes. Toxicol Lett 2015, 237:191-199

56. Iliopoulos D, Jaeger SA, Hirsch HA, Bulyk ML, Struhl K: STAT3 activation of miR-21 and miR-181b-1 via PTEN and CYLD are part of the epigenetic switch linking inflammation to cancer. Mol Cell 2010, 39:493-506

57. Chen M, Liu Y, Varley P, Chang Y, He XX, Huang H, Tang D, Lotze MT, Lin J, Tsung A: High-mobility group box 1 promotes hepatocellular carcinoma progression through miR-21-mediated matrix metalloproteinase activity. Cancer Res 2015, 75: $1645-1656$

58. Zhou X, Ren Y, Liu A, Han L, Zhang K, Li S, Li P, Kang C, Wang X, Zhang L: STAT3 inhibitor WP1066 attenuates miRNA-21 to suppress human oral squamous cell carcinoma growth in vitro and in vivo. Oncol Rep 2014, 31:2173-2180

59. Usui H, Shibayama M, Ohbayashi N, Konishi M, Takada S, Itoh N: Fgf18 is required for embryonic lung alveolar development. Biochem Biophys Res Commun 2004, 322:887-892

60. Franco-Montoya ML, Boucherat O, Thibault C, Chailley-Heu B, Incitti R, Delacourt C, Bourbon JR: Profiling target genes of FGF18 in the postnatal mouse lung: possible relevance for alveolar development. Physiol Genomics 2011, 43:1226-1240

61. Surette AP, Madureira PA, Phipps KD, Miller VA, Svenningsson P, Waisman DM: Regulation of fibrinolysis by S100A10 in vivo. Blood 2011, 118:3172-3181

62. Piecha D, Wiberg C, Mörgelin M, Reinhardt DP, Deák F, Maurer P, Paulsson M: Matrilin-2 interacts with itself and with other extracellular matrix proteins. Biochem J 2002, 367:715-721

63. Ichikawa T, Suenaga Y, Koda T, Ozaki T, Nakagawara A: DeltaNp63/BMP-7-dependent expression of matrilin-2 is involved in keratinocyte migration in response to wounding. Biochem Biophys Res Commun 2008, 369:994-1000

64. Tam CW, Liu VW, Leung WY, Yao KM, Shiu SY: The autocrine human secreted PDZ domain-containing protein 2 (sPDZD2) induces senescence or quiescence of prostate, breast and liver cancer cells via transcriptional activation of p53. Cancer Lett 2008, 271: 64-80

65. Termén S, Tan EJ, Heldin CH, Moustakas A: p53 regulates epithelialmesenchymal transition induced by transforming growth factor $\beta$. J Cell Physiol 2013, 228:801-813

66. Yeung ML, Tam TS, Tsang AC, Yao KM: Proteolytic cleavage of PDZD2 generates a secreted peptide containing two PDZ domains. EMBO Rep 2003, 4:412-418 